\title{
Influence of forms and cutting edge front surface knife indicators for power reduction of wood
}

\begin{abstract}
Rational use of waste wood is one of the most important tasks of complex processing of wood raw material. For use different dreequilibrium waste in the production of woodcement materials and solid biotop- Lib necessary to grind them on special shaving machines. Thus requirements placed on the quality of the crushed timber to manufacture a specified, limited primarily wood particles size and content of impurities, which allows to evaluate the effectiveness of the cutting elements during grinding total timber volume in chip size required only by the value of the cutting force or its derivatives. In most cases when cutting drevesi us rake angle of the cutting tool is constructively postoyannoy value (the length of the cutting edge), and the cutting edge can be straight, Inclination to Nome, a triangular shape or radius. Qualitative indicators Vågå circular cutting process the cutting tool with the above mentioned forms obtained by treating wood materials with carbide circular saws plastically us. Power indicators cutting process (with identical conditions) as a dreveSina and wood materials are scarce, while using a cutting tool having a stepped shape of the cutting edge and the front surfaces STI, and multiple cutting corners, practically absent. A study of the present is directed to finding optimum parameters of the cutting tool (cutter), providing the lowest energy costs for the primary comminution milling. Experimental studies were carried out on an especially setup allows you to simulate the process of chopping wood Frederic zerovaniem. Used five types of knives with different geometric for- we are cutting edge and front surfaces. The effectiveness of any type of blades evaluated torque value. As a result of comparative analysis of all forms of cutting elements define the most effective form of tive knife, the dependence of the torque supplied to the static cutting knife pine three main lines of cut.
\end{abstract}

Keywords: grinding wood milling, the optimum shape of the knife, the experimental setup, the torque flow to the knife, chopping wood power rates

\section{Introduction}

The integrated use of wood has been and remains one-Noah of the most relevant for industries engaged in the workpiece, the first customer handling and processing of timber. ${ }^{1}$ So far, in all of Russia is beneficial not used half, and separately in Siberia - up to two-thirds of the biomass of a tree. ${ }^{2}$ The AAC, which reaches across the country $550 \mathrm{Mm}^{3} /$ year, is used in average only $35 \%{ }^{3}$ Production of almost all technological operations in forestry development, treatment or processing of wood due to the formation of wood waste are secondary wood resources. From them or with their supplements can produce new products. ${ }^{4}$ Wood wastes are lump (solid) and soft (sawdust, shavings, dust). ${ }^{5}$ Wood waste depends on the type and location of their formation. ${ }^{4}$ By wastes include logging residues (twigs, branches, stubs, crown, thin-Dimensional illiquid wood, tree trunks and debris and al.), Their volume is $22 \ldots 26 \%{ }^{5}$ On woodworking enterprises - is gor-were slats otkomlevki, trim, shavings, chips, their volume - $25 \%$ and above. ${ }^{5}$ On plywood - is pencils, veneer-flaw, trimming the logs, bark, sawdust, plywood trimming, dust, etc., and their volume of $50 \ldots 55 \%{ }^{5}$ Waste container production reach $32 \%-46$ parquet] 0 . By $\%$ whisker [kovye waste timber cutting in the country is processed mainly in the wood chips, ${ }^{6}$ is used for this disc and drum chippers. ${ }^{7}$ Rational primary grinding process timber opredelyaet-Xia minimum power consumption and a good cut quality, producing a specified particle size timber. ${ }^{8}$ With decreasing thickness the chip cut by cutting the specific work (work expended on the conversion per unit volume in the chips drevesi- us) increases due to the fact that for the separation of any volume dre- Vecino into fine particles is required to expend more work than in the deletion Research Institute for larger.
Volume 2 Issue 3 - 2018

\section{EO Bulatasov,VP Popov,VP Hanin}

Department of Food Biotechnology, Orenburg State University, Russia

Correspondence: EO Bulatasov, Department of Food Biotechnology, Orenburg State University, Pobeda, I3, Orenburg, Russia,460018,Email eduard190319@mail.ru

Received: May 28, 2018 | Published: June 08, 2018
Thus, from the standpoint of reducing power consumption for cutting if necessary converted into a certain amount of wood chips is more advantageous to cut thick chips, remembering that the quality of the treated surface thus deteriorating. ${ }^{9}$ In some industries (e.g., woodcement materials - GOST P 54854-2011, hydrolysis -OGST 18320-78, solid n-biotite Lebanon - GOST 54220-2010 and 55553-2013 GOST, polymer composite materials - GOST 16361-87) quality requirements chopped dre-Vecino dimensions limited primarily wood particles and impurities containing Niemi. In order to reduce power consumption for cutting during the initial comminution timber for the above production iz must grow shallow wood chips in a large thickness, and power rates to the process of grinding in this case are basic. As an equipment for grinding wood cutting prime- nyayut special particle machines, which differ in the structure of the cutting mechanism and the feeder and appointment view feedstock. ${ }^{10}$ Particle machines are of the following types of cutting mechanism design: bowls, milling, disc, drum, rotor-channels. ${ }^{11}$ A cutting mechanism equipped with cutting tools bonded instruments in the form of knives, cutters, teeth, finding optimal parameters of which is the subject of research. The purpose of this study - determination of the optimum shape PE cementitious tool (knife) in dependence on the geometrical shape of its PE zhuschey edge and the rake face when a primary grinding drevesi us milling in the axial, radial and tangential directions to obtain the desired chip size.

\section{Objects and methods of research}

To conduct the study design was developed experimental setup (Figure 1), which allows simulating the process of grinding milling 
timber. The installation includes a power and measurement modules as well as the mechanism supplying structurally formed in one frame. The power module consists of a circular shaft mounted on the bearing mediated rah. On the shaft with keyed connections fixed disk whose parameters are selected depending on the cutting conditions. In this experiment used a $132 \mathrm{~mm}$ disk diameter and $12 \mathrm{~mm}$ in width. According to the thus formed conductive disk has two symmetrically arranged groove, in which establishes a knife. The diameter of the disk set of knives is $156 \mathrm{~mm}$. To exclude a Departure knives and their rigid fixing in grooves provided on the clamp back portion of the knife. All the knives are different of one another geometric shapes of cutting edge and the rake face, ime-dissolved width of $12 \mathrm{~mm}$ and a protrusion on the disc surface of $12 \mathrm{~mm}$ (Figure 2). Measuring installation module (Figure 1) can adjust the torque depending on the cutting forces arising on the cutting edge of the knife. As the torque sensor applied dynamometer device-parameter. The feed mechanism of the "slide" is moved along the guide pillars perpendicular to the axis of rotation of the cutting instrumen- ta. On the slide there are a pressing device and aligning plates between which the workpiece is clamped. Feed by rotating mahovich- ka mounted on the spindle, which nut is secured on the frame, the screw is itself connected to the carriage. installation drive provides static or dynamic. Studies were conducted under the following conditions: static cutting skoe; cutting circle diameter $\mathrm{d}=156 \mathrm{~mm}$; Cutting width $12 \mathrm{~mm}$; Rear angle $\alpha=15^{\circ}$; cutting angles $\delta=65^{\circ}$ (knife № $1,3-5$ ) and $\delta=55,60,65^{\circ}$ (knife № 2); sharp knives; Knife material - ressorno- alloy spring steel 60S2G (GOST 14959-79); infeed knife $\mathrm{Sz}=1 . . .12 \mathrm{~mm}$; po- kind of wood - Pine (density $\rho 12=0,40 \mathrm{~g} / \mathrm{cm}^{3}$ ); wood humidity $\mathrm{W}=18 \%$. № knife 1 has a cutting edge radius shape and rectilinear hydrochloric front surface. Knife № 2 differs stepwise cutting edge and the stepped front surface (three steps). Angle PE zaniya first stage $\delta=55^{\circ}$, second $-60^{\circ}$, third $65^{\circ}$. № knife 3 has a single-nostoronny cutting edge inclination (angle oblique sharpening $\omega=14^{\circ}$ ) and single- sided front slope surface. For knife № 4, as for the blade № 2, characterized by a three-step shape of the cutting edge and the rake face, but the cutting angle for all three stages of the same $\delta=65^{\circ}$, the second stage has a slope-sided front surface (oblique angle za- point $\omega=26^{\circ}$ ), being a smooth transition between the the first and third stupenya- mi. Knife № 5 has a straight cutting edge and a straight front surface. Classification of forms of blades adopted in accordance with., ${ }^{2,4,6,12,13}$ Cutting was performed by applying torque to the operating shaft. When this torque is measured depending on the feed to the knife.

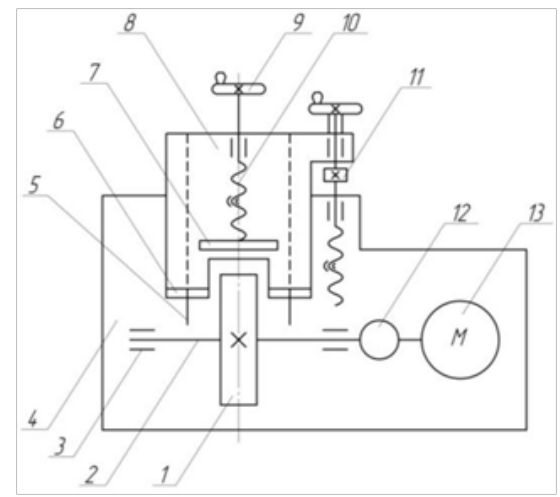

Figure I Kinematic experimental setup is. I: the blade disc; 2 : a shaft; 3 : the bearing assembly; 4: bed; 5: guide Bearing; 6: a thrust plate; 7: presser plate; 8 : slide; 9: mahovi- choke; 10: screw with a nut; II: drive; I2: dynamo metric unit; 13: the electric motor.

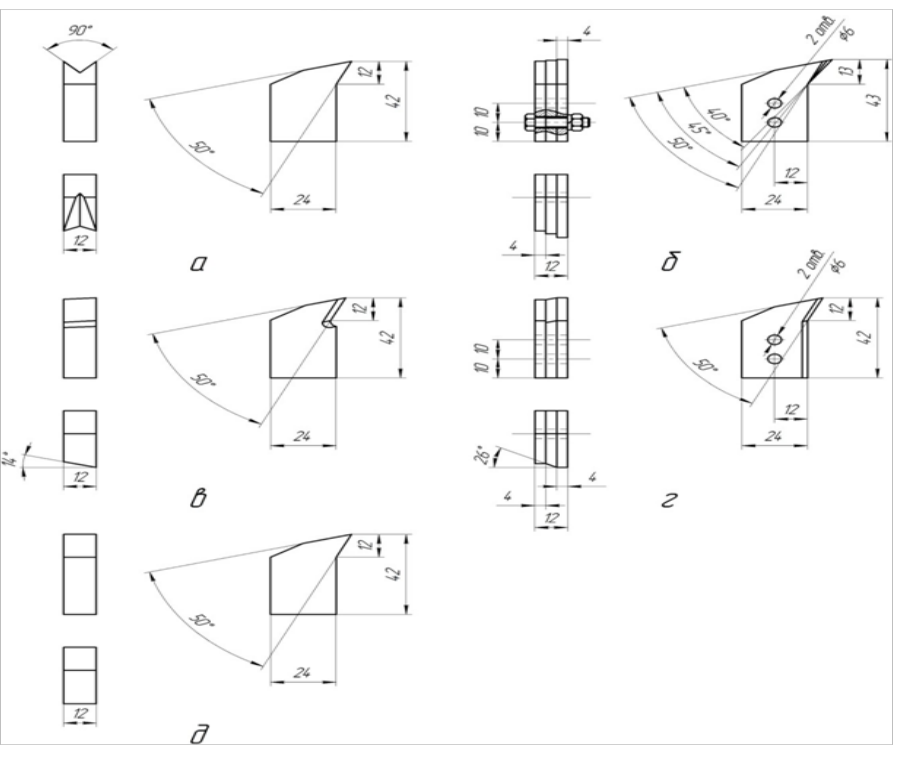

Figure 2 Construction knives: and - a knife № I; b - № 2; in - № 3; g - № 4; d - № 5 .

\section{Results and discussion}

\section{As a result of research found the following.}

When cutting along the grain of wood chips were obtained in a curved shape in cutting the wood across the grain at small feeds - short and brittle chips, consisting of separate elements loosely connected to each other at high feed - element chip, but more strongly associated between svya- a. Sometimes, during the chip cutting large thickness in the lateral direction occurred splitting the work piece along volokon. When cutting wood butt obtained partially scattered chips. When cutting wood knife (№ 5) with a rectilinear cutting edge and the rectilinear front surface able to cut chips: along fibers - at supply $\mathrm{Sz}=12 \mathrm{~mm}$ in the end - when $\mathrm{Sz}=8 \mathrm{~mm}$, transverse fibers - when $\mathrm{Sz}=7 \mathrm{~mm}$. In rare cases, able to cut chips of greater thickness, as when applying the above values occurred blade jamming in the wood. When cutting knife № timber 5 at small feeds thickness arr a- chip being operated commensurate with the feed quantity. When cutting along the grain dreve- Sina when $\mathrm{Sz}=12 \mathrm{~mm}$ chips formed middle of the thickness - 9mm (valid for all blades). This is because the loan srechips deformed front edge of the knife and squeezing between the body of the cutting tool and the workpiece. When cutting the rods stru-large thickness (at $\mathrm{Sz}=12 \mathrm{~mm}$ ) fibers along different knives their amount was approximately the same. The experimental data have established the connection between the torque $\mathrm{M}$ and serving knife $\mathrm{Sz}$ and construct graphs of this dependence for the three main cases of cut (Figure 3).

Analysis of the results revealed a general increase of krutyaschemoment in the case of increasing the supply to the cutting blade under static timber used for all of the cutting elements, which agrees with data. ${ }^{14-16}$ At cutting chip thickness 7 and $8 \mathrm{~mm}$ knife (№ 5) with a rectilinear cutting edge and the rectilinear front surface considered for the three main directions of cutting revealed that the greatest torque is formed by cutting across the fibers. It exceeds the torque for mechanical and slitting with o- responsibly in 1.1 and 1.3 times. Comparative analysis revealed that similar power rates are ime- № knives 2 and 3, as well № 4 and 5. The shape of the knife № 2 in the 
cutting process provides better infeed (delay) of the knife on the pitch $\mathrm{Sz}=12 \mathrm{~mm}$, which is associated with a smaller wedge angle of the first and second stage of this knife $\left(\beta 1=40^{\circ}, \beta 2=45^{\circ}\right)$ compared with all other angles of taper ments HO- $\left(\beta=50^{\circ}\right)$. 3 № knives having a sharp cutting edge in comparison with the straight cutting edge of the knife № 4 provides a-smaller Difficult you on grinding energy. Due to the inclined front surface № blades 2, 3 and 4 in the cutting process creates the best conditions for chip removal. The surface under the front of the knife, which contributes to reduction Indeed hydrochloric cutting force. Radiused cutting edge of the knife form № 1 conventionally comprises two cutting edges having versatile inclined relative to each other. These cutting edges are sharper as compared with a straight cutting edge of the knife 5 № cutting effect and provide external ${ }^{12}$ the surface treated material. Tilting knife edge by an oblique sharpening leads to kinematic knife sharpening; the cutting conditions are created sliding, which provides a Chi--empty and easy cutting ${ }^{11}$ fibers. Radius form knife edge № 1 allows dividing the load on the comminuted wood on the time of the cutting forces, and the cutting force required to remove the chips, is distributed between the two vertices radiusknife. Since for cutting the wood chip with crack formed anticipatory, propagating the pattern with a certain speed, it means the destruction of wood and gradually goes They attribute for easier cutting of fibers are locally changing voltage over time at the cutting edge of the knife (with its introduction into the timber) should occur more smoothly and gradually. This requirement ensures that the geometric shape of the blade number 1 .

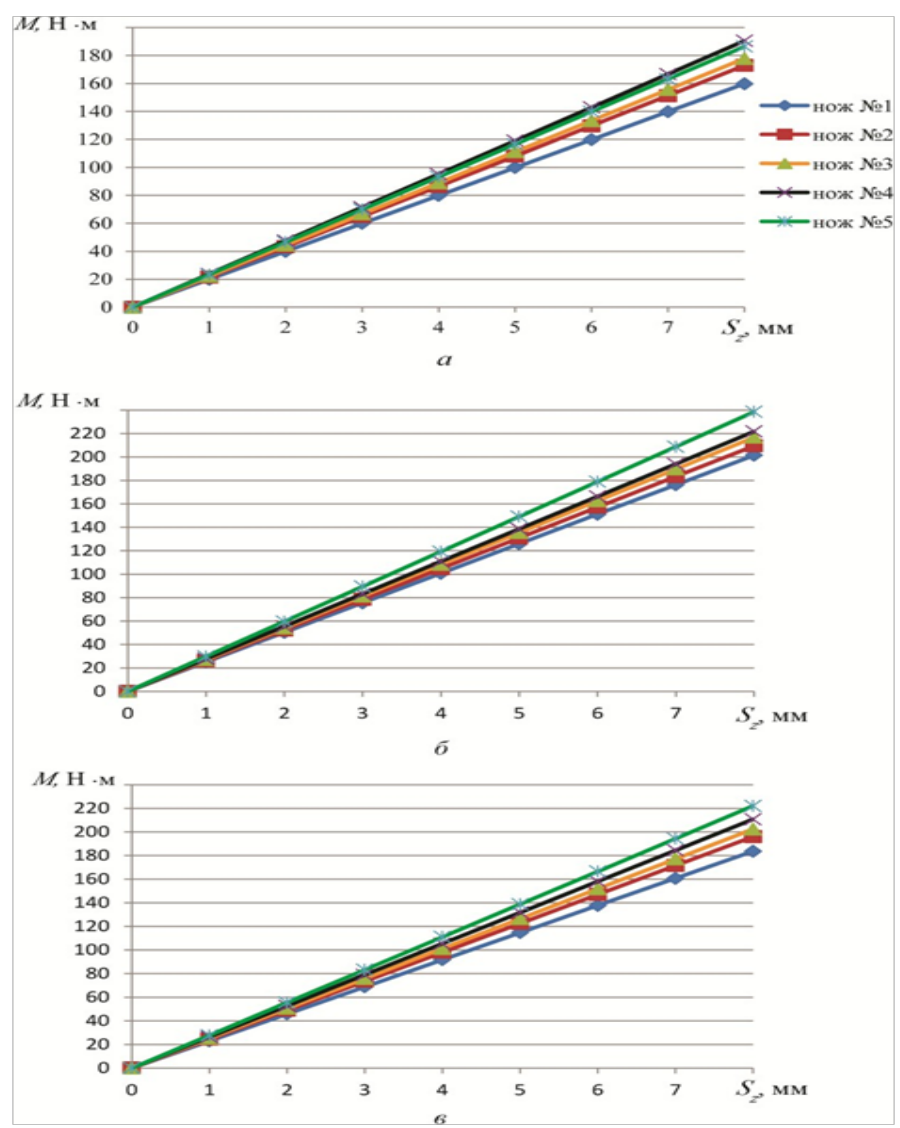

Figure 3 The dependence on the torque supply to the knife milling pine.And: along the fiber (section plane radial); b: perpendicular to the grain (cutting speed parallel to a tangential axis); in: in the end (transversaltangential plane)

\section{Conclusion}

1. According to the results, it can be considered the most effective radius of the cutting edge shape and the corresponding shape of the front surface of the blade.

2. Comparison of the experimental data with the corresponding parameters of cutting wood in the dynamic mode may be used to explain the influence of the cutting speed on the cutting force and its derivatives.

3. Knives proposed design with minor modifications may be used in the construction of the rotary cutter and milling izmelchi-teley stumps.

\section{Acknowledgements}

None.

\section{Conflict of interest}

Authors declare that there is no conflict of interest.

\section{References}

1. Zakharenko GP. Integrated use of wood. Yosh Kar Ola STU. 2006;104.

2. Pankiv OG, Demin LN, VN Parshikova, et al. The efficiency of processing of wood greens of fir various methods. $J$ Math issled. 2012;1:168-171.

3. Gerasimov YY, Syunèv VS, Sokolov AP, et al.Sound use of wood and forest residues for bioenergy: Estimation of potentials and technological specifications approaches. Sci Zh Cube GAU. 2011:73(09):4.

4. Sazhin VS, Titunin AA, Novikov AN. Complex use dre- Vecino. Kostroma STU. 1997;82.

5. Gomonay MV. Production of fuel briquettes. Wood raw materials, equipment, technology, modes of operation: monograph. MSFU. 2006;68.

6. Otlev IA, Steinberg TSB. Handbook of chipboards. Forest promst. $1983 ; 40$.

7. Fellers NM, Litzman EP. Chippers: monograph. Forest Promst.1980;96.

8. Manzhos FM. Wood cutting machines. $2^{\text {nd }}$ edition. Rev Forest promst. $1974 ; 456$.

9. Zalegaller BG, Swallow PV, SP Boykov. Technology and equipment for timber yards: Textbook. for high schools. $3^{\text {rd }}$ edition. Rev Ext Forest promst. 1984;352.

10. Demidov Yu. Grinding wood for the production of wood chip boards. Forest promst. 1974;144.

11. Bershad AL, Tsvetkova NI. Cutting wood. Minsk Vysheyshayashk. 1975;303.

12. Morozov VG. Woodcutting tools. Forest Promst. 1988;344.

13. Shpisskhofer $\mathrm{T}$. Rotary cutter for shredding particularly bulky. Relative moves US Pat.1999;10.

14. Beniak J, Ondruska J, Cacko V. Design Process of Energy Effective Shredding Machines for Biomass Treatment. Acta Polytechnica. 2012;52(5):133-137.

15. Strehler C. Development of Near Net Shaped Si3N4 / SiC Composites with Opti- mised Grain Boundary Phase for Industrial Wood Machining. Eng Sci Diss Freiberg. 2011;90.

16. Weber A. Magnetostriktive Schnittkraftmessungen beim Holzfräsen. Holz als Roh- und Werkstoff. 1962;20(12):486-492. 